\title{
Achieving a transparent and visual automotive value chain with ICT-support
}

\author{
Jan Ola Strandhagen, Arne Horten and Kristian Martinsen \\ Raufoss Technology AS, Sindre Bolseth, NTNU
}

\begin{abstract}
Raufoss Chassis Technology (RCT) manufactures wheel suspension parts in aluminium for cars. Large volumes of identical parts, fully automated production lines combined with the extreme demands on speed, precision and quality makes fast response to changing demands important for the overall competitiveness. The manufacturing unit has been built and implemented based on Lean Manufacturing and Extended Enterprise Principles. The concept of extended enterprise is directly applicable, and provides a platform for understanding, discussion and decision. The need to establish basic principles prior to the development of solutions is important. The need for a common visual description of the value chain is vital. Showing the value chain, its partners and material flow, the information flow, the processes etc.

The Extended Enterprise model, along with other tools and methods, have proven useful, but far from complete. The case also shows that there is still lack of flexibility in $\mathbb{E R P}$ systems. RCT has a very simple BOM ( 2 levels) and the ERP system should not force a complicated and resource-demanding planning process onto the company! As a consequence the strive for Lean ICT solutions must continue, where the systems and the use of them can be upsized or downsized in fluctuation with the product range, product complexity, demand fluctuations and emerging markets. The need to achieve transparency without creating nervousness is an important challenge when allowing huge amount of information to be available throughout the value chain. Indicators of performance and status of the value chain flows are important. The RCT case is an example of how theory, models and concept can directly be applied to support industrial development. And the case feeds back updated needs for further research and development on Extended Enterprise and Supply Chain Management.
\end{abstract}

Keywords

Extended Enterprise, Lean production, Supply Chain Management, Automotive Value Chain, Logistic model, Forrester effect, Transparency, Visualisation.

\section{INTRODUCTION}

The absolute requirements of quality, cost and delivery (speed and precision) in the automotive business are well known. The OEMs have standardised processes for information and goods flow from suppliers. But company-individual needs and solutions from suppliers like Raufoss Chassis Technology (RCT) can improve overall Value Chain Performance. How can these effects be achieved? The same 
challenges are applicable in the other end of the Value Chain for a $1^{\text {st }}$ Tier supplier. Suppliers with varying standards and solutions regarding processes and information system must be integrated into RCT's unified processes. RCT is working to develop its` supply chain to be able to meet these challenges.

RCT is developing and manufacturing chassis components (Figure 1) for the automotive industry. RCT has more than 20 years experience in this market segment. Due to a larger contract with General Motors (GM) for the Epsilon Platform (Opel Vectra, SAAB 9-3 etc.), RCT has built a new plant at Raufoss in Norway to serve the European plants of GM. A duplication plant is built near Montreal in Canada to serve US clients. Start Of Production (SOP) was January 2002 at the Raufoss plant, and is scheduled to be Sept 2003 at the Canada plant.

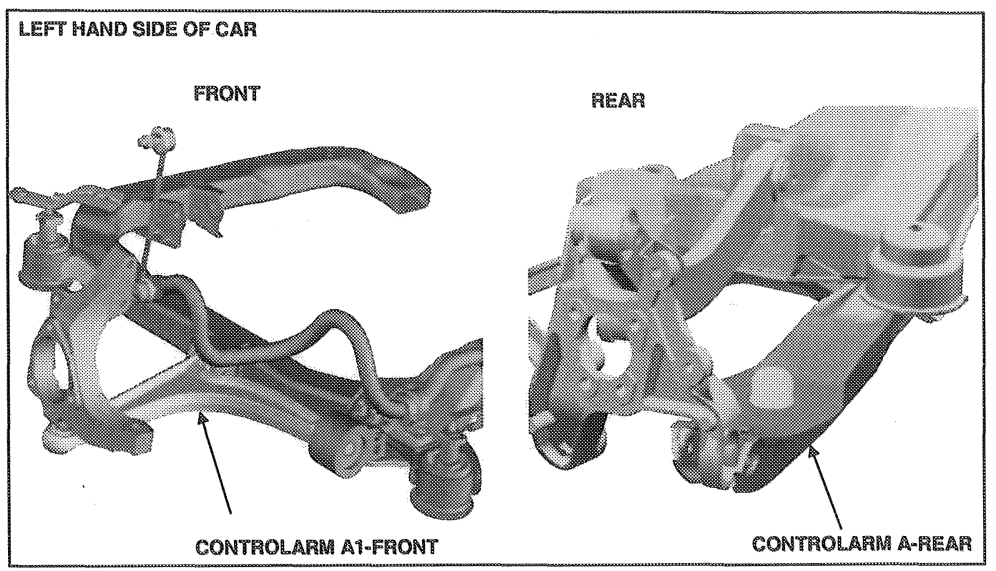

Figure 1-RCT products on GM cars

The parts are identical for all possible variants within the Epsilon platform, although the labelling and packaging requirements differ from car-plant to car-plant. The Raufoss plants are each designed to a meet the capacity requirements for a single source supplier to GM. The manufacturing in each plant is organised in two fully automated manufacturing lines where all handling of the parts is automated trough robots and conveyors.

The front arm is distinguished in left and right, while the rear is identical left and right. For the front arm the same subcomponents are used, but the machining process creates different shapes of the left and right arm. The RCT supply chain is not complex in matter of number of suppliers: There are 14 different assembled parts from 7 different suppliers in addition to the aluminium parts.

Extruded aluminium profiles and rods are delivered from three different suppliers. Suppliers are located in Europe and USA. Some of the suppliers have very long lead times: up to 10 weeks. Even though there is general GM contract, there are call-offs from $7 \mathrm{GM}$ plants in Europe, and a similar number of plants in USA. Logistically this acts as different customers. 


\section{BACKGROUND}

To meet the challenges of RCT it was decided to base the development of the Value Chain and Logistic System on well know and approved theory, and develop solutions based on these. A thorough process was established and a study of theory was performed. For sake of completeness the most important theoretical background for the project is given here.

Throughout the 1980's and 1990's the concepts of customer and supplier integrative relationships gained renewed attention. Business in general began to develop extremely close relationship with selected clients, often called strategic customers, and significantly more emphasis was placed on improving working arrangements with suppliers (Bowersox et al., 1999). This trend with increased collaboration throughout the supply chain, could be explained as a result of three factors (Browne et al., 1995):

* Manufacturing takes place in a global context where local markets are subject to global standards

- Manufacturing systems are required to develop and operate environmentally benign products and processes

- The business and organisational structures, within which manufacturing operates, are under increasing stress

The driver behind such collaboration was the desire to extend the control and coordination of operations across the entire supply process, replacing both the market and vertical integration as the means of managing the flow process (Schary and Skjøtt-Larsen, 2001).

The concepts of Supply Chain Management, Extended Enterprise and Supply Chain Transparency are contributions to reach these ideas. The objective of these concepts is to move all partners in the supply chain onto a common platform of Logistics transactions and information systems for greater interorganisational "seamlessness" or transparency. This integration can result in significant faster system response times to volatile changes in marketplace events and patterns of demand (Boyson et al., 1999). Solutions based on all these concepts contributes in creating a Lean Value Chain.

\section{Supply Chain Management}

Supply chain management (SCM) can be defined as (Simchi-Levi et al., 2000): " a set of approaches utilised to efficiently integrate suppliers, manufactures, warehouses, and stores, so that merchandise is produced and distributed at the right quantities, to the right locations, and the rights time, in order to minimise systemwide cost while satisfying service level requirements". 


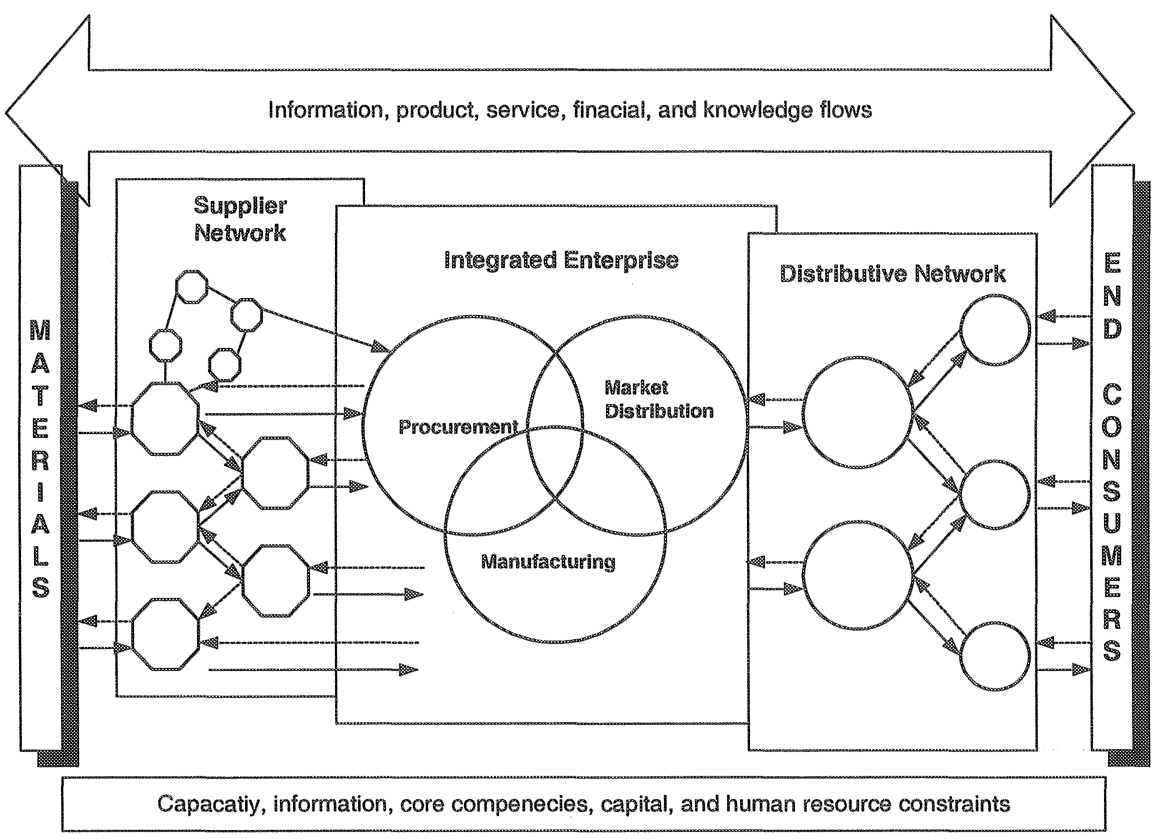

Figure 2 - Supply Chain Model Source: Supply Chain Faculty, Michigan State University

Logistics can be defined as (Christopher, 1998): "the process of strategically managing the procurement, movement and storage of materials, parts and finished inventory (and the related information flows) through the organisation and its marketing channels in such a way that current and future profitability are maximised through the cost-effective fulfilment of orders".

The supply chain both extends the logistics concept and creates an organisational system with its own attributes. More the linking operational units together, supply chain management deals with the full scope of supply activities; production, procurement and distribution.

Houlihan (1986) has summarised the characteristics of supply chains as:

w The supply chain is a complete process for providing goods and service to final users

- Membership includes all parties, including logistics operations from initial material supplier to final user

- The scope of supply chain operations include procurement, production and distribution

w Management extends across organisational boundaries to include planning and control over operations of other organisational units

- A common information system accessible to all members makes coordination possible between organisations

- Member organisations achieve their own individual objectives through the performance of the supply chain as a whole 
Both the definition and the characteristics of the supply chain place great emphasis on the integration of the different components in the supply chain. Integration stresses the coordination of a network of separate operations to achieve common objectives in a material and product flow. Information sharing and operational planning are the keys to successfully integrate the supply chain.

\section{Forrester effect}

A typical effect on less integrated supply chains, is how small changes in downstream demand are dramatically amplified upstream. This is known as the Forrester effect or Bullwhip effect. This has been discussed by: Alfnes and Strandhagen (2000), Simsci-Levi et al. (2000) and McCullen and Saw, (2001).

There are many causes to these effects:

- Uncertain forecast Gives increased variance upstream

- Long lead times Requires buffers and stocks to compensate

- Large Batch sizes Gives larger variations than actual need upstream

- Price variations Creates variations in demands

* Hamstring Customer orders more than real demand

In a supply chain, information sharing in real-time is pointed to as one major implementation to avoid these effects.

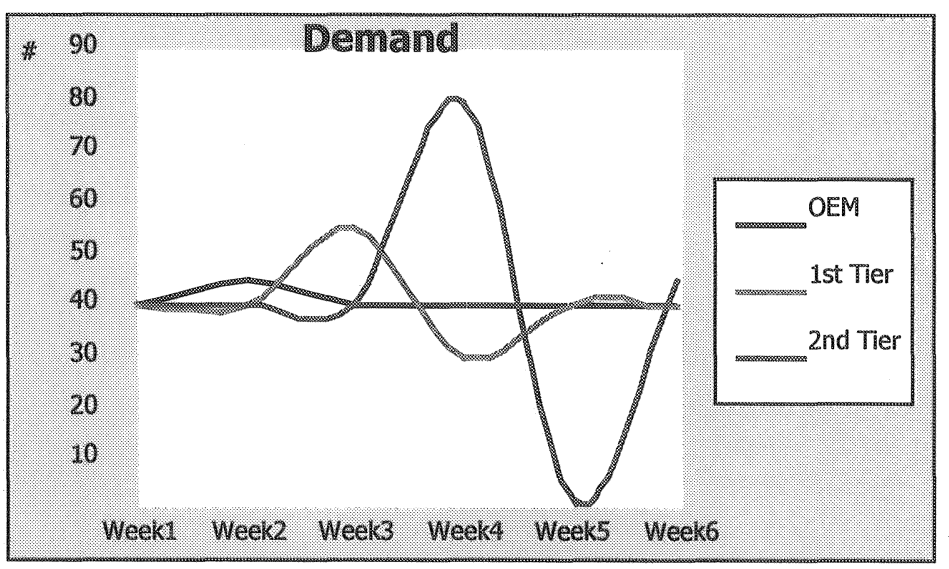

Figure 3 - Forrester effect

\section{Transparency and real-time information flow}

Towill and McCullen (1999) have presented four material flow control principles, and have demonstrated their successful application by means of an industrial case study. McCullen and Saw (2001) further discuss this. A central point in this study was how to avoid the Forrester effect. The four principals are: Control System, Time Compression, Information Transparency and Echelon Elimination. 


\section{Extended Enterprise}

According to Jagdev and Browne (1998) new approaches have emerged in Manufacturing, including Agile Manufacturing (Kidd, 1995), (Dove, 1996), Extended Enterprise (Browne et al., 1995; O'Neill and Sacket, 1994; Busby and Fan, 1993; Caskey, 1995), and Virtual Enterprise (Goldmann and Preiss, 1991; Parunak, 1994; Doumeingts et al., 1995).

Figure 4 presents a generic model as depicted by Jagdev and Browne (1998). This generic model is based on the understanding of the Extended Enterprise in terms of business processes. The model identifies the main building blocks for assembling an Extended Enterprise environment. The models show a systematic approach to integration and coordination across the various players. Each of these blocks can be further divided into several detailed building blocks.

This generic model represents a functional view of a manufacturing enterprise. The business model is composed of a vertical and a horizontal axis. The vertical axis, is composed of design, manufacturing and control issues, therefore representing the traditional, functional view of a manufacturing system. The vertical axis also represents the flow of information between the various functions and manufacturing. The horizontal axis represents the integration of the supplier, distributor and customer with the manufacturing system in an Extended Enterprise. The horizontal axis also represents the flow of materials/products from the supplier, through to the customer.

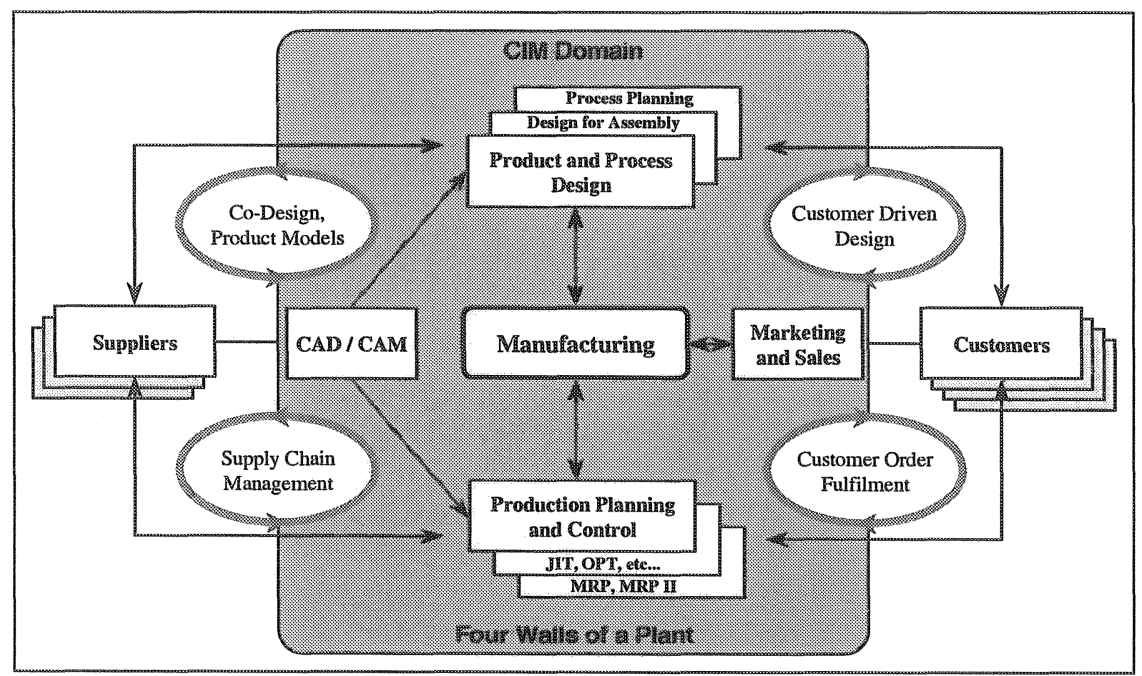

Figure 4 - Generic model for the Extended Enterprise Jagdev and Browne (1998)

According to Jagdev et al. (1998) the model also identifies five high-level macro business processes. Each of these macro business processes can be decomposed further to show in greater detail the sequence of activities within the process. The macro processes identified are directly related to the operational activities of the manufacturing enterprise. The five macro business processes, and 
their associated definitions, identified using the business model shown above are as follows, (Jagdev and Browne, 1998):

- The Customer Order Fulfilment process includes all of the activities directly involved with the planning, control and coordination of customer requirements with the manufacturing process and the delivery of the product to the customer.

m The Supply Chain Management process includes all of the activities directly involved in the coordination of supplier capabilities, the planning of supplies requirements and the delivery of these requirements to the manufacturing process.

- The Manufacturing process contains all of the activities directly involved in the physical production of the product.

- The Customer Driven Design process includes all of the activities directly involved in the design and development of a product (and its associated manufacturing process) subject to customer requirements and its release to manufacturing.

* The Co-engineering and Co-Design process includes all of the activities directly involved with the coordination of supplier capabilities into the product design process.

Jagdev \& Thoben (2001) points out that to days supply chains in reality are enterprise networks, and has collected and developed a set of characteristics (an anatomy) of bilateral relationships. This anatomy can be used two ways. To determine the nature of the relationships, and to give advice on focus area of development for establishing the relations.

\section{ERP-systems in Manufacturing}

The term ERP (Enterprise Resource Planning) was first introduced by Gartner Group in the beginning of the nineties (see www.gartner.com). But of course the principles and software goes further back. Already in the seventies, some of the larger integrated software programs did appear (SAP, Oracle, JD Edwards, Baan, etc.). The development of the functionality of the ERP-systems began even earlier, with the Bill of Material Processor (BOMP) in the 1950's. This was followed by Material Requirements Planning (MRP, late 50's), Closed Loop MRP and MRPII (late 70's).

Traditionally, the enterprise had many different computer systems and databases to support its various functions. An ERP-system is a standard application program, which support execution of business processes throughout the whole company. The ERP-system has functionality that makes the company able to replace many of their applications with a single seamless system with one common database.

Looking outside the factory walls, the Distribution Resource Planning (DRP) systems can support the material logistics planning between actors in the network if the units are using the same ERP-system and database. The last 2-4 years the ERP vendors have introduced their SCM solutions, which promise e.g. multi-enterprise visibility, collaboration, and intelligent decision support and execution capability for the value chain. The basic element in this solution is the APS (Advanced Planning and Scheduling) application. The APS offer functionality like demand planning, 
supply network planning, and transport planning and available to promise. The APS transmit and receive information from the whole supply chain through EDI or XML, and the information is processed in order to get optimised plans and forecast for the future.

\section{Lean Production}

The ERP based approach follows a traditional mass production strategy, and are seldom sufficient to handle the low volumes and demand variety that characterise current markets. An alternative approach is lean production. During the last decades, several enterprises have achieved flexibility and increased competitiveness by implementing the "lean" or "just-in-time" principles developed at Toyota (Womack \& Jones 1996). The basic purpose of lean production is to increase profits by reducing costs through completely eliminating waste such as excessive stocks or work force. To achieve cost reduction, production must promptly and flexibly adapt to changes in market demand without having wasteful slack time. Such an ideal is accomplished by the concept of JIT: producing the necessary items in the necessary time (Monden 1998).

Lean/JTT manufacturing is based on simplified fast flows that are coordinated by shop floor people to meet real demand. Supply on real demand requires that workin-progress and throughput times are minimised to ensure responsiveness. In lean production, teams are tightly linked in customer-supplier connections. These can typically interact with each other in a predictable sequential manner. The focus is turned towards process improvement. Activities, connections, and production flows are standardised and rigidly specified to provide the necessary performance and flexibility to supply a wide range of standardised products at low costs.

\section{THE RCT SUPPLY CHAIN CHALLENGES}

\section{The customer requirements}

As something between a $1^{\text {st }}$ and $2^{\text {nd }}$ Tier supplier to automotive industry, RCT is facing extreme demands from the customer. Zero defects and $100 \%$ precision of delivery are obligatory. Continuous improvement is a must since prices are decreased by contract every year. The combination of these demands, the high volumes of identical parts, and the fully automated manufacturing, makes RCT very vulnerable to any kind of disturbances. From the Operations perspective of the company the overall competitiveness is dependent on the ability to manufacture and deliver with:

- Zero defects

w Full precision of delivery

a Fast responses to changes required from the OEM

- Correct and speedy information flow 
To be able to operate our business and achieve our business goals this certainly leads to the general requirement of being able to: Minimise total costs. Supply chain integration with a transparent information flow is one of the key parameters to achieve this. The concept of transparent information flow applies to RCT internally as well as the whole supply chain.

\section{The RCT challenges}

As described in earlier sections the logistic complexity of our parts and manufacturing processes are extremely low:

a The speed of the production rate is constant (run by a certain speed or stand still)

a The number of levels in our Bill Of Material is 2

- The customers are defined through life-time contracts

- GM-standards for supply specifies much of the logistics processes between the companies

From logistics point of view the main challenges resulting from our customers and our own requirements are:

a No defects or deviations are allowed in the logistics process (quantity, delivery time windows, labelling, etc)

- The extreme speed of production and delivery, combined with limited space and equipment for storage allows no stop of flow to make corrections

- Variations in information (process and quality) between plants of GM

- Format and technical means (fax, Email and EDI)

- Frequency (weekly, biweekly, daily as well as extraordinary)

- Time horizon (20 weeks, ten weeks, fortnightly)

- Accuracy (varies more than $100 \%$ on weekly basis)

In order to meet these challenges a thorough development process of the entire logistics and information systems of RCT were needed. The key elements in the changes were:

- Redefine control principles of the entire Value Chain, abandoning the MRP/ERP principles where not applicable

- Implement new, flexible ICT solutions integrated with existing ERP-system

- Establish new types of relations with all suppliers

- Internal organisational changes regarding responsibility, tasks and reporting routines

\section{THE RCT SOLUTION}

The development process was performed through a number of steps. The steps are designed based on the Control Model Methodology (Strandhagen and Alfnes). 


\section{The process}

From half a year ahead of Start of Production (SOP), the follow project/process steps were performed

- Define basic challenges for RCT (results presented in 3.2)

- Define basic principles to be applied to meet these challenges

- Describe logistics model and information flow, the concept and control principles. The model is named RCT Extended Enterprise Model, and further developed into RCT Operations Model

- Establish Supply Chain Management Centre (SCMC)

- Define Key Performance Indicators (KPI)

- Develop processes and ICT support

\section{Basic principles applied}

Process integration, information transparency, and a lean organisation were understood as vital to achieve a competitive supply chain. A set of basic principles was decided to rule the game of development and operations of the Supply Chain. These principles, based on the well known principles and RCT challenges are:

- Time focus: The need to be precise and speedy in all our processes, physical as well as administrative

- Lean manufacturing: Focus on value adding processes only.

- One-way flow and tasks done once: Focus on streamlining the flow of goods and information, and be sure that all tasks are done at once, and only once.

- Real-time information: All decisions and actions must be taken based on realtime information access

- Transparent Value Chain: Information sharing throughout the supply chain. Information from customers, our own company, as well as suppliers should be transparent through the whole value chain

- Integrated processes: Seek to integrated processes, both within the company as well as with our partners. Integration of processes by ICT

- Visual and Simple: Keep everything as simple as possible, and visualise whatever can be visualised

\section{The RCT Extended Enterprise concept, control principles and RCT Operations Model}

Based on the concept of the Extended Enterprise we defined our RCT Extended Enterprise model. This model was used to communicate and create understanding about the relations between all development and operational process; how they were linked, and how they influenced each other. 


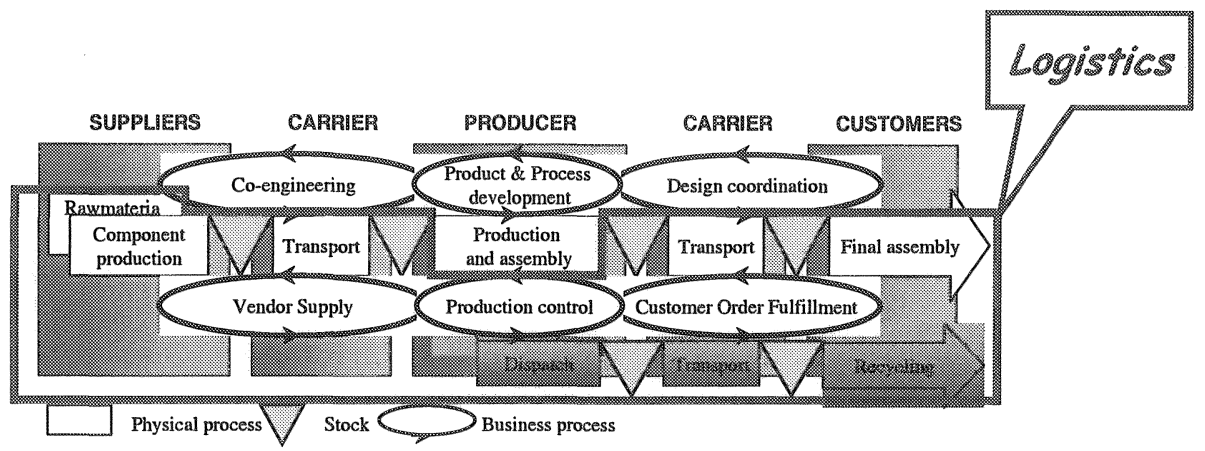

Figure 5 - The RCT Extended Enterprise Model

The RCT Extended Enterprise Model was extremely important in this process, and created the common platform for the decisions that were made. It was also the basis for the decision to organise all logistics processes into one organisational unit; the Supply Chain Management Centre. In our latest development we have expanded and renamed the model to RCT Operations Model as it is being implemented on out Intranet.

\section{Supply Chain Management Centre (SCMC), transparency and real-time information flow}

At the Raufoss Plant, all supply chain processes are performed in a Supply Chain Management Centre, with a dedicated group of people have a complete and shared responsibility for all Value Chain processes related to information and flow of goods. This centre coordinates all transactions regarding the RCT node in the supply chain. The SCMC is established based on the concept of Single-point-ofcontact, and facilitates the value chain orientation of the organisation rather than a functional orientation.

By applying the basic principles it has been possible to establish control principles for the complete flow of goods, and these principles again implemented through the ERP system. Transparent information flow implies, immediate flow of correct information needed for controlling the processes. Each node can "see trough" the supply chain downstream as well as upstream. Information from OEM such as year plans, forecasts and call offs are in true time available trough the supply chain. The challenge is of course to facilitate this without creating a nervous system where all plans are updated whenever a tiny change in numbers have occurred. The way to realise this is to create an automated filter on demand changes. It works so that changes in forecast and call-offs within a certain range does not affect changes (i.e. no plans are changed and sent) in down stream call-off, but the information is made available down the value chain. The obvious media to implement this is of course the Internet. An illustration of the solution can be seen from the following Figure . 


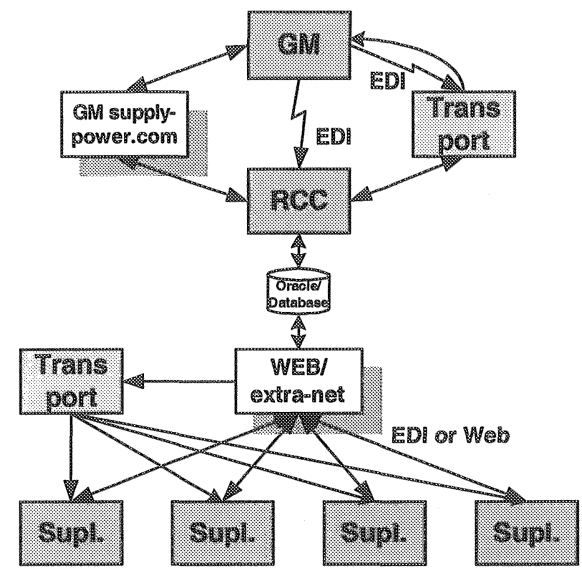

Figure 6 - Information flow and availability

GMSupplyPower is an initiative by GM to empower suppliers to conduct business online. At the GMSupplyPower site each function in GM is divided into Powers, e.g. Material Power, Finance Power etc, where all the desired information regarding this function can be found.

\section{Visualisation and Key Performance Indicators}

Similarly to the transparency in the supply chain, RCT has implemented visualisation of material flow and manufacturing process status for manufacturing operators. In addition to ensure fast response to changes, this supports the teambased organisation and a highly motivated work force. Maintenance, tool changes etc. are easier to synchronise to the manufacturing rate.

Internally, information on changing demands etc. should be passed on to shop floor operators, maintenance etc. This makes the RCT manufacturing system able to respond to the changes, make fast alternation in plans, etc. The coordination of maintenance and manufacturing is a typical area where fast ant transparent information flow is beneficial. Each operator will have a special designed "control panel" where all the vital information is visual at any time, if not the operator choose to go into details on the data, which is available trough the intranet. The operator has a graphical picture of the manufacturing line with status signals. Green means that everything is running correctly, Yellow is a warning that some parameters is out of control, Red is alarm that something has gone wrong or some parameters are outside tolerance limits. A Yellow warning light will not stop the line, but a red alarm will. This is similar to the Toyota ANDON principle (Monden, 1998). The most important process parameters and production data is displayed as well. Figure 7 shows an example of such a control panel. 


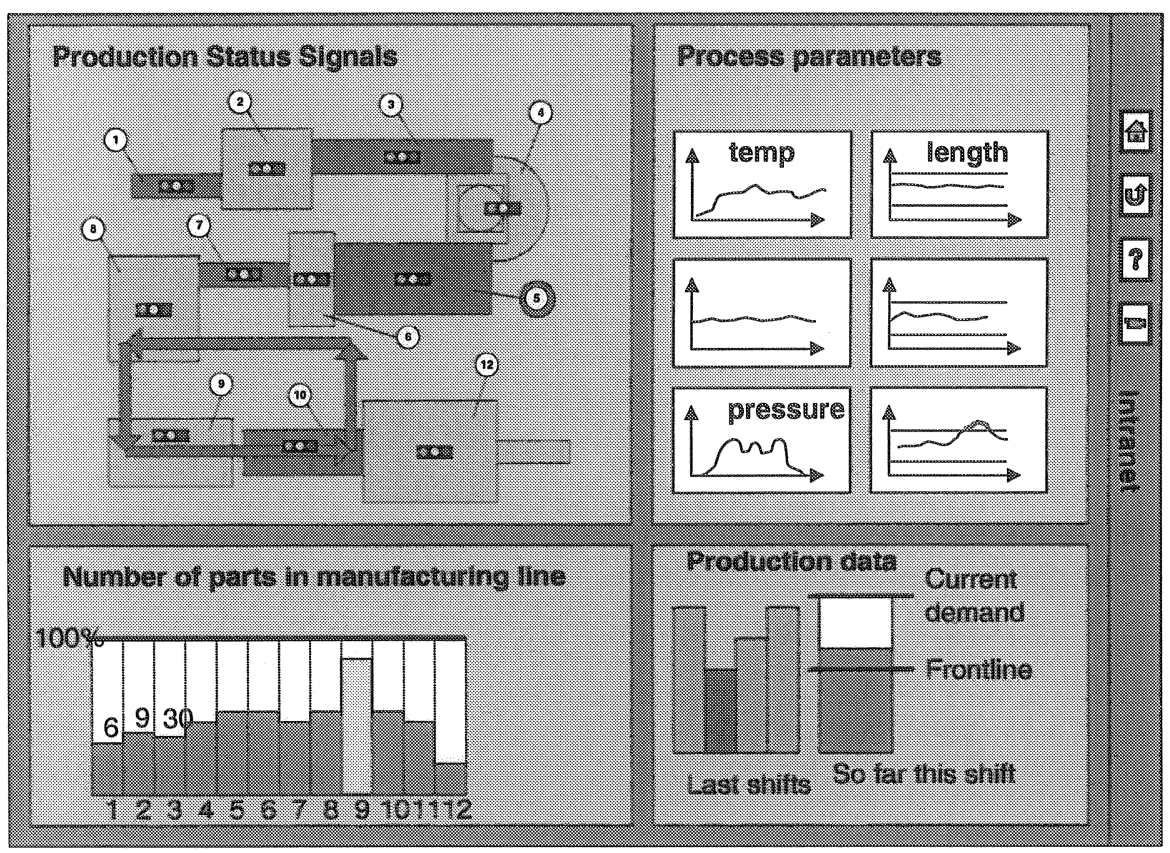

Figure 7 - Example of Dashboard for operators of manufacturing line

A similar dashboard has been developed for the Supply Chain Parameters. In addition to the standard parameters on delivery precision, PPMs, lead time etc, the following parameters have been established.

- Key parameters to display the change coefficient for value stream throughput. This coefficient are aggregate measures to display the changes in past and future, making it possible to extract tactical information from the exact operative information along the value chain

- Key parameter for plan stability and quality. These parameters are displaying the frequency and the level of change of the volumes of the plans.

The Supply Chain dashboard is shown in Figure 8. The buffer factor indicates the changes in the buffer-sizes over the last 4 weeks period. A similar factor not shown in Figure displays to which degree that the stock size is "harmonising" with the needs in the production. The volume factor indicates the volume of goods delivered for the last period compared to the previous period. Another factor not shown in Figure displays the actual delivered volume compared to the forecasted volume four weeks earlier. The first plan quality indicators shows number of changes done in the production plan the last four weeks. The second factor shows the difference between the highest and lowest planned volumes for the current week that has occurred in the plans over the last twenty weeks. 


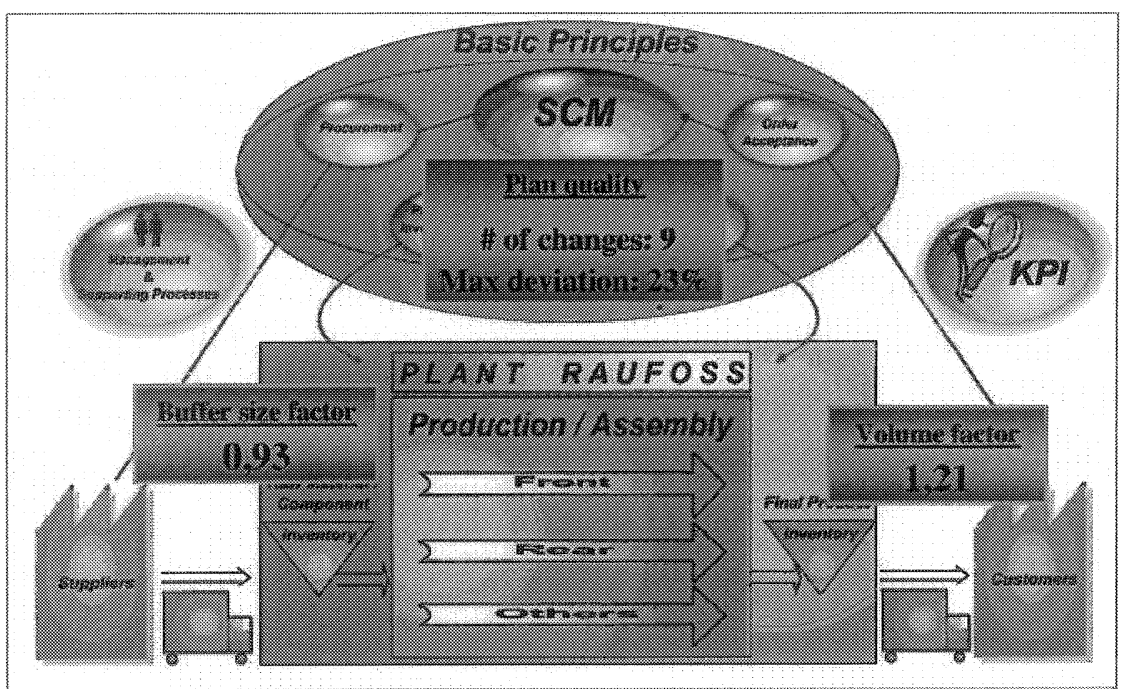

Figure 8 - Example of Dashboard for the Supply Chain

\section{TOPICS FOR FUTURE RESEARCH}

In this paper we have described the theory behind, the principles and the practical solutions for a car part manufacturer. There are several interesting discussions arising from this story, discussion that should be elaborated and brought as topics into future, cross-disciplinary research projects. These topics are briefly dealt with in this section.

Possession of information is often considered as an important source of power, both towards suppliers as well internally in the organisation. The concept of transparency and shared responsibility involves, however, a multidisciplinary coordination of work processes and hence a cultural change in information management. The paper describes how the implementation was done, how the supply chain information transparency is achieved through a transformation from a functional to a process oriented organisation, and how Raufoss could cope with these organisational challenges.

The OEMs have standardised processes for information and goods flow from suppliers. But individual needs and solutions from suppliers can improve overall Value Chain Performance. How can these effects be achieved? What sort of process will make it possible to obtain them. Will standardisation and technological solutions allow "plug in and plug out" of entire value chains, with all its relations and processes.

The same challenges are applicable in the other end of the Value Chain. Suppliers with varying standards and solutions regarding processes and information system must be integrated into RCT unified processes.

Another important aspect in a global community is to be able to "copy", move or transform value chains established around a single plant location to their locations 
and other plants. These challenges are in fact being studied and a methodology sought to be developed in the Growth 5 FP project MOMENT GRD1-2001-40488.

\section{CONCLUSIONS}

Through this project both the researchers from NTNU and SINTEF, as well as the RCT personnel has gained considerable new experience and insight. Of general interest the following should be mentioned

m The concept of extended enterprise is directly applicable, and provides a platform for understanding, discussion and decision

a The need to establish basic principles prior to the development of solutions is important. There is still a strong tendency in industry to believe that technology and solutions can be purchased and implemented as black boxes without any impact to how the company will be organised and operated. To establish principles, and support them by technology and solution is therefore important

- The need for a common visual description of the value chain is vital. Showing the value chain, its partners and material flow, the information flow, the processes etc. The Extended Enterprise model along with other tools and methods have proven useful, but far from complete. Future development of models, methods and tools are required. Tools that link to information systems for automated extraction and model building.

- The flexibility of ERP systems is improved, but is still not sufficient. RCT has a very simple BOM ( 2 levels) and the ERP system should not force a complicated and resource demanding planning process onto the company!

- As a consequence the strive for Lean ICT solutions must continue, where the systems and the use of them can be upsized or downsized in fluctuation with the product range, product complexity, demand fluctuations and emerging markets.

- The need to achieve transparency without creating nervousness is an important challenge when allowing huge amount of information to be available throughout the value chain.

* The need to establish indicators that describes the past, the present and the future status of the value chain as well as the quality of our control of the material flow is vital.

The RCT case is an example of how theory, models and concept can directly be applied to support industrial development. And the case feeds back updated needs for further research and development on Extended Enterprise and Supply Chain Management.

\section{ACIKNOWLEDGEMENTS}

This work has been performed as an integral part of the development of RCT along with research and development work performed by a number of researchers from NTNU and SINTEF. RCT, represented by Vice President Tor Giæver deserves 
a lot of thanks for believing and supporting the research and development ideas from SINTEF and NTNU, and pursuing these ideas into the company. And for the openness in sharing these ideas and results in public.

In addition to the authors valuable contributions have been made by Geir Ole Sletten, Erlend Alfnes and Odd Jøran Sagegg in preparing this paper. It is also important to thank Paul Higgins of CIMRU for his input on the Extended Enterprise concept description.

\section{REFERENCES}

[1] Alfnes, E., Strandhagen J.O., 2000, Enterprise Design for Mass Customisation, Int. journal of logistics, vol 3, \#2, July.

[2] Bowersox, D. J., Closs, D. J. and Stank, T. P., 1999, $21^{\text {st }}$ Century Logistics: Making Supply Chain Integration a Reality, Michigan State University.

[3] Boyson, S., Corsi, T.M., Dresner, M.E. and Harrington, L.H, 1999, Logistics and the Extended Enterprise Benchmarks and Best Practices for the Manufacturing Professional, John Wiley \& Sons, inc., New York.

[4] Browne, J., Sackett, P. J. and Wortmann, J. C., 1995, Future manufacturing systems towards the extended enterprise, Computers in Industry, Vol. 25, pp 235 - 54.

[5] Christopher, M., 1998, Logistics and Supply Chain Management: Strategies for reducing costs and improving service, Pitman Publishing, London.

[6] Houlihan, J. B., 1986, Intenational supply Chain Management, International Journal of Physical Distribution and Materials Management, Vol. 15, nr. 1.

[7] Jagdev, H.S. and J. Browne, "The Extended Enterprise - A Context for Manufacturing", Invited Paper, International Journal of Production Planning and Control, Volume 9, No. 3, 1998.

[8] Jagdev, H.S. and K-D. Thoben, Anatomy of enterprise collaborations, Production Planning and Control, 2001, Vol12, No5.

[9] McCullen, P., Saw, R., 2001, Designing the Agile Supply Chain, p. 129 - 136, Proc. of The International Symposium on Logistics, Salzburg Austria.

[10] Monden, Yasuhiro, 1998, Toyota Production System - An Integrated Approach to JustIn-Time, Engineering \&Management Press, Norcross, Georgia.

[11] Schary, P. B. and Skjøtt-Larsen, T., 2001, Managing the Global Supply Chain, Copenhagen Business School Press, Copenhagen.

[12] Simchi-Levi, D., Kaminsky, P. and Simchi-Levi, E., 1999, Designing and Managing the Supply Chain - concepts, strategies and case studies, MacGraw-Hill, Boston.

[13] Simsci-Levi, D., et al, 2000, Designing and Managing the Supply Chain, McGraw-Hill.

[14] Towill, D.R, McCullen, P.L., 1999, The Impact of Agile Manufacturing on Supply Chain Dynamics, The international Journal of Logistics Management, 10(1) 83 - 96. 